\title{
OBITUARY
}

\section{In Memoriam: Professor Hannu Alaranta, 20 May 1947-10 June 2008}

Spinal Cord (2009) 47, 428; doi:10.1038/sc.2009.6

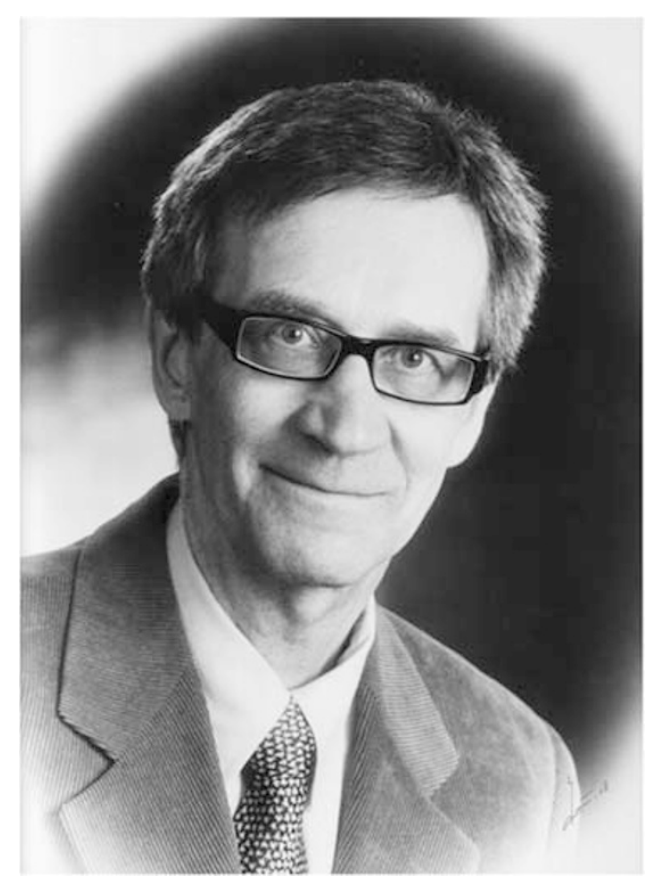

Hannu Alaranta passed away in June 2008, suffering from serious illness, in Helsinki, Finland. He was a great scholar and a good athlete. He graduated from the University of Helsinki in 1973, became a specialist in Rehabilitation and physical medicine in 1980, earned his PhM in 1985 and specialized in Sports and Exercise Medicine in 1988. He became Professor in 2006.

His work focused on rehabilitation and sports for people with disabilities. Hannu Alaranta's career spanned internationally too. He worked as a medical officer in Jugoslavia, Croatia and Bosnia-Herzgovina on Rehabilitation Medicine organized by the World Health Organization in 1996-1997. He was a member of ISCoS (International Spinal Cord Society) and Academie Europaenne de Medicine de Readaptation.

Hannu Alaranta served as a senior physician in the Rehabilitation Unit of the Invalid Foundation in Helsinki in 1986-1994, and thereafter as a director of Käpylä Rehabilitation Centre (Finnish Association of People with Mobility Disabilities) in Helsinki.

Professor Alaranta has left a remarkable effect in the field of Rehabilitation Medicine and Science in Finland.

He leaves his wife, two children and two grandchildren.

Eija Ahoniemi A colleague of Hannu Alaranta Käpylä Rehabilitation Centre, Helsinki, Finland E-mail: eija.ahoniemi@invalidiliitto.fi 